\title{
Scaled-down Cluster mission aims for relaunch in 1999
}

Munich. The Cluster satellite mission will be relaunched in 1999, provided that the European Space Agency (ESA)'s science programme committee approves a scaleddown plan, as expected, later this month. Cluster's original four satellites were destroyed when its Ariane-5 launcher exploded during its maiden voyage in June.

Last week, ESA's space science advisory committee voted unanimousiy to support a relaunch, despite the overall project cost of ECU210 million (US\$166 million) which the committee fears will have a significant impact on its long-term space science programme, Horizons 2000.

According to the committee, the costs of the relaunch could be met by reshuffling the financing of Horizons 2000 after 1998, postponing by six months the launch of the next cornerstone mission a satellite dedicated to infrared and submillimetre astronomy - and delaying by two years a planned 'mediumsized mission' dedicated to Solar System science.

The new Cluster will be made up of the project's original spare satellite, Phoenix, and three smaller identical

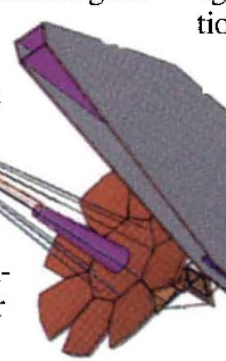
Uncertain future: Cluster's relaunch could affect the Nex Generation Space Telescope.
Next Generation Space Telescope (NGST).

The committee will meet in January to 'brainstorm' the overall programme, in order to ensure that it is set on a reliable track once again. ESA prides itself on the stability of individual programmes that, thanks to long-term planning, protects it from the political uncertainties suffered by US space science programmes. But it fears this stability may be threatened because the financial reshuffling required by the Cluster relaunch leaves little financial buffer.

Also on the agenda of the January meeting will be ESA's participation in the Hubble space telescope after 2001. That year will see the expiry of a ten-year international agreement that recognizes ESA's contribution to Hubble's infrastructure and instruments. The agreement guarantees the agency's space scientists 15 per cent viewing time and 15 per cent participation in Hubble's scientific review panels.

A working party to negotiate a new agreement was set up last month by ESA and the US National Aeronautics and Space Administration (NASA). But this time ESA has satellites, which will probably be built by German aerospace company Dornier. The four satellites are likely to be launched in two batches, one pair by Ariane- 4 and the other by Ariane- 5 , at a cost that is expected to be kept down to ECU60 million.

According to Cluster's project manager, John Credland, most of the scientific aims of the mission will be saved. But ESA member states have so far been unable to produce enough money to replace all the instruments that were on the original four spacecraft.

Credland says there will even be a benefit from the delayed flight of Cluster. The mission will be able to analyse in three dimensions the Earth's electrical and magnetic fields as they interact with solar wind particles, as the satellites will benefit from maximal sunspot activity. This will occur in 2001 and 2002.

But the committee remains concerned that the relaunch could have a long-term impact on the Horizons 2000 programme, which plans space science missions for the next 20 years. The programme includes two further cornerstone missions - a mission to Mercury and an interferometry observatory - and a series of medium-sized missions. Also included are possible international collaborations in projects such as the international space station, the Hubble space telescope and its possible successor, the little bargaining power. Hubble is to be refurbished in 1997 and 1999 to extend its life to at least 2005. In 2002, during the final planned refurbishment, the original hardware contributed by ESA will be replaced by updated NASA hardware, and instruments will be added. Because of a shortage of money, ESA's science programme has been unable to compete to provide new instruments.

One controversial negotiating tool that the committee may consider is the promise of significant participation in NGST, a project that is as yet very vague both in design and financing. The European astronomical community is lobbying ESA to ensure continuing participation in Hubble and NGST.

Piero Benvenuti, head of the ESA Space Telescope European Coordinating Facility, in Garching near Munich, says that access to the space telescopes will be of particular importance when the European Southern Observatory's Very Large Telescope (VLT), now being built in northern Chile, comes into operation in 2000 .

'Most of Hubble's biggest successes have been follow-ups to objects observed with the Keck's telescope in Hawaii," he says. "Space telescope follow-up by the VLT of objects identified with Hubble or the NGST will be of utmost importance for European astronomers." Alison Abbott

\section{Rocket failure leads to grounding of small US satellites}

Washington. The US National Aeronautics and Space Administration (NASA) has suspended further launches of small satellites after a malfunctioning Pegasus rocket led to the loss of two scientific missions last week. Daniel Goldin, NASA administrator, called the moratorium until a newly formed review panel can assess the agency's options for putting small payloads safely into orbit.

Goldin has made no secret of his impatience with the US launch industry, particularly Orbital Sciences Corporation, the manufacturer of Pegasus, for a string of launch failures and delays that has been a stumbling-block for the agency's 'cheaper, faster' philosophy of small science missions (see Nature 381, 541; 1996).

Both the HETE (High Energy Transient Experiment) and the Argentine SAC-B science missions are believed to be total losses after the third stage of an air-launched Pegasus-XL rocket failed to separate from the satellites in orbit. SAC-B, which was primarily an engineering test of Argentina's first satellite, carried instruments to observe the cosmic X-ray background and hard X-rays from solar flares.

HETE was an international mission led by NASA and the Massachusetts Institute of Technology, with partners in France, Japan, and Italy. Its primary focus was on gamma-ray bursts; scientists had hoped it would be able to locate optical counterparts to these mysterious objects.

Although neither satellite was expensive by the standards of space missions, costing just over \$20 million each, their loss is "an embarrassment" admits Alan Bunner, who heads NASA's high-energy astrophysics programme. Goldin immediately ordered the agency's chief engineer, Daniel Mulville, to head a task force to consider the agency's options for launching small satellites.

Mulville says his team will consider how NASA managers can better assess risk and reliability, how much flexibility the agency has to switch launch vehicles under current contractual agreements, and whether it could expand its launch options to include non-US vehicles.

At present, only two US launchers are available for small satellites: Pegasus and the LMLV (Lockheed-Martin Launch Vehicle), which also failed in its first and only try last year.

Missions that could be affected by the moratorium in the short term are the SWAS (Submillimeter Wave Astronomy Explorer) scheduled for a Pegasus launch in January, and the Lewis and Clark satellites, the first of which is set for an LMLV launch on 20 December.

Tony Reichhardt 